Practical Applications of Spectrum Analysis By Dr. Herbert Dingle. Pp. ix $+245+19$ plates. (London: Chapman and Hall, Ltd., 1950.) 40s. net.

GOR more than half a century there has poured 1 from what has become known as "Fowler's Laboratory" at the Imperial College of Science and Technology, London, a steady stream of research papers on spectroscopy. Little on technique has, however, been published; and to those who knew something of the great variety of problems success. fully tackled in the laboratory, it had seemed possible that much accumulated practical experience handed down from Lockyer and Fowler, and added to year by year, might be lost except to their direct successors.

The appearance of this welcome book has now averted this danger. Prof. Herbert Dingle, himself for long Fowler's right-hand man, has distilled into its pages the essence of nearly thirty years of experience in the practical application of the spectroscope to chemical analysis. Though it is in no sense a work on theoretical spectroseopy, enough background in optics and atomic structure is given to enable the laboratory worker to make the most intelligent use of his instruments. Armed with this book and a table of wave-length identifications, the practical spectroscopist should be able to attack analytical work in any field of study in which the method is at all applicable.

As is perhaps inevitable in the present state of knowledge, little space is given to quantitative analysis, where the author contents himself with laying down general principles without descending to empirical methods of limited application. A long chapter is devoted to a detailed discussion of the line spectra of individual elements, in particular their behaviour as traces in mixtures; this and the excellent collection of spectrograms reproduced in halftone make the book worth its admittedly high price.

\section{Induction Heating}

By N. R. Stansel. Pp. viii+212. (London : McGrawHill Publishing Co., Ltd., 1949.) 34s.

$$
\mathrm{T}
$$

HE heating of metals by the induction of eddy currents in the material to be heated is now a well-established industrial operation; the induction furnace has its own field in the metallurgical industry, and induction equipment for surface-hardening and other operations requiring a brief but accurately controlled heat cycle is widely used in mechanical engineering. There are already a number of books on the subject, some expounding the principles for the benefit of electrical engineers who are concerned with the making of the equipment, and others chiefly concerned with describing the uses of a comparatively new tool.

This present book is certainly not in the latter class, but it is none the less difficult to regard it as an exposition of principles; it is much more of the nature of a handbook of formulæ and data relating to the electrical and thermal quantities involved. The chapters are broken into very short and some. what disjointed paragraphs, and any formula required is stated quite baldly with almost no explanation or discussion. The author makes a point of representing nearly every equation by a curve, which admittedly enables the reader to visualize the rise and fall of the quantities, but it is difficult to believe that without a more adequate discussion he would be able to judge whether the curve had any application to his own work. The data collected from many sources may well be useful to the engineer already familiar with the subject. It is a nice point whether he will prefer to find his magnetic induction given in "kilolines per square inch" as it is in some places, or in "gausses" which appear in others.

L. H.

\section{High Vacua}

Principles, Production and Measurement. By Dr. Swami Jnanananda. Pp. xiii +310 . (New York : D. Van Nostrand Co., Inc.; London: Macmillan and Co., Ltd., 1947.) 41s. net.

R. SWAMI JNANANANDA'S book is written from the point of view of a physicist rather than a technologist, and therefore starts with a full chapter on the kinetic theory of gases. This explanation of vapour pressure, viscosity and molecular streaming forms an excellent theoretical background to vacuum practice. The succeeding chapter on pumps gives a fairly complete description of most types of mechanical, molecular and diffusion pumps using both mercury and high-boiling-point organic liquids, although the widely used. Kinney mechanical pumps and the silicone fluid for diffusion pumps have unfortunately been omitted. The section on gauges covers manometers, and McLeod, Pirani, viscosity, ionization and radiometer gauges, the last type in great detail considering its limited popularity. One notable omission is the cold-cathode discharge tube, particularly Penning's very useful modification. The least satisfactory section of the book is that on vacuum systems, as it tends to concentrate on the older 'sealing wax' techniques, and omits rubber gaskets, Wilson spindle seals and modern glass-to-metal seals.

Apart from the criticism of omission, the book is readable, clearly illustrated, well referenced and indexed, and is a useful addition to the vacuum physicist's bookshelf.

R. O. JENKINS

\section{Acetylene and Carbon Monoxide Chemistry} By John W. Copenhaver and Maurice H. Bigelow. Pp. xvi+357. (New York: Reinhold Publishing Corporation; London: Chapman and Hall, Ltd., 1949.) $80 s$. net.

THIS book is based on a report, presumably that published by Charles A. Meyer and Co. as P.B. Report 18852-S, which was written by J. W. Reppe while he was detained, under the supervision of one of the authors, by the United States Army in 1945. The plan of the book closely follows that of the report, all of which is substantially included but amplified and with the addition of information drawn from the reports of post-war investigators into the German chemical industry and other literature.

After a chapter on the synthesis of acetylene and its reactions at atmospheric pressure, the authors devote the remainder of the book to reactions at high pressure, with chapters on vinylation, ethinylstion, the reactions of ethinylation products and one on polymerization to cyclooctatetraene and its reactions, the first two chapters having appendixes giving lists of the products obtainable and their melting or boiling points, and the last an appendix giving details of the derivatives of cyclooctatetraene. The book concludes with chapters on the reaction of acetvlene with carbon monoxide, the preparation and reactions of acetylene homologues and finally the practical aspect, namely, details of experiments on the explosion of acetylene and the technique and equipment for its safe handling under pressure--a subject not discussed in Reppe's report. 